\title{
ENCAPSULATION LAVENDER OIL BY SPRAY DRYING FOR SPORTSWEAR
}

DOI: 10.35530/TT.2021.23

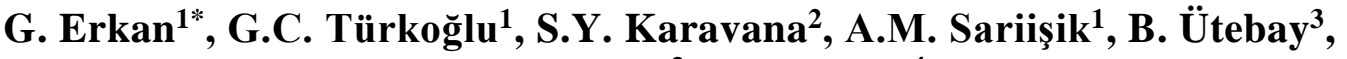 \\ A.Ç. Bakadur ${ }^{3}$, A. Popescu ${ }^{4}$
}

${ }^{1}$ Dokuz Eylul University, Textile Engineering, İzmir, Turkey

(E-Mail: gokhan.erkan@deu.edu.tr,gizem.turkoglu@deu.edu.tr, merih.sariisik@deu.edu.tr)

${ }^{2}$ Ege University, Faculty of Pharmacy, Department of Pharmaceutical Technology, İzmir, Turkey

(E-Mail: sinemyaprak@hotmail.com)

${ }^{3}$ Uniteks, R\&D Center, İzmir, Turkey

(E-Mail: burcin@uniteks.com.tr, aysegul.cetmeli@uniteks.com.tr)

${ }^{4}$ National Research Development Institute for Textiles and Leather, Bucharest, Romania

(E-Mail: alina.popescu@incdtp.ro)

\begin{abstract}
Microencapsulation technology has been increasingly used in textile industry due to give some peculiarities such as controlled released etc. In this study we aim to make aromatherapy sportswear using lavender oil. Lavender oil is encapsulated by different wall materials. Microcapsules were obtained by spray drying method. Differential scanning calorimetry, thermal gravimetric analysis, Fourier Transform infrared spectroscopy, morphological analyses were applied to microcapsules. Optimum microcapsules were applied to different fabrics. Fastness to washing and rubbing, SEM and antibacterial tests were carried out.
\end{abstract}

Keywords: aromatherapy, lavender oil, microencapsulation, spray drying, textile finishing

\section{INTRODUCTION}

Microencapsulation is a technique used to protect active substances from external influences by coating them in small droplets. This technology has preferably been used in the pharmaceutical, chemical and food industries to preserve and prolong fragrance, flavour or therapeutic effect [1,2]. Microencapsulation applications have succeeded in becoming one of the products that add value in the textile industry, create a competitive environment and difference, and increase its market share. In this study, it is aimed to obtain essential oil from Lavandula angustifolia plant, which has a pleasant smell and known antibacterial effect [3], and to use it in textile products. In this way, while the effect of this product, which has a limited lifespan, will be increased, and alternative sports and leisure clothes will be developed.

\section{MATERIALS AND METHODS}

In this study, knitted fabric from different natural and synthetic fibres was used. Gelatin (Gel), gum arabic (GA) and ethyl cellulose (EC) was used as shell material. Gel 
was kindly donated from Sel Gel. Sigma-Aldrich branded GA and EC was employed. Lavender oil used as core material was obtained from by Doğal Destek A.Ş. (Tabia). Tween 80 was used as a surface-active agent and obtained from Merck. Tanatex Nano PU was employed as a binder. All other auxiliary chemicals used in the study are technical grade.

Plants grown in the Southern and Central Aegean were harvested and lavender essential oil was obtained by using the water vapour distillation method. The composition of the essential oil was determined by gas chromatography-mass spectrometry (GC-MS). Microcapsules were obtained in different shells and core ratios using selected polymers by spray-drying method. The solutions prepared at the different concentrations were sprayed from the $0.5 \mathrm{~mm}$ nozzle into the spray dryer cabinet. The formulation of lavender oil capsules are given in table 1 .

Table 1. Formulation of Lavender oil microcapsules

\begin{tabular}{|c|c|c|c|c|c|c|}
\hline Formulation & Polymer & $\begin{array}{c}\text { Lavender } \\
\text { oil } \\
(\%) \\
\end{array}$ & $\begin{array}{c}\text { Pump } \\
\text { speed } \\
\text { (ml/min) } \\
\end{array}$ & $\begin{array}{c}\text { Inlet } \\
\text { temperature } \\
\left({ }^{\circ} \mathrm{C}\right) \\
\end{array}$ & $\begin{array}{l}\text { Outlet temperature } \\
\qquad\left({ }^{\circ} \mathrm{C}\right)\end{array}$ & Yield (\%) \\
\hline L1 & \multirow{3}{*}{$5 \%$ Gel } & 4 & 10 & 140 & 90 & 34.2 \\
\hline L2 & & 6 & 5 & 140 & 90 & 31.9 \\
\hline L3 & & 8 & 5 & 140 & 90 & 32.8 \\
\hline L4 & \multirow{2}{*}{ 3\% Gel } & 5 & 2.5 & 125 & 85 & 37.7 \\
\hline L5 & & 10 & 2.5 & 125 & 85 & 26.6 \\
\hline L6 & 2.1\% Gel & 0.5 & 2.5 & 125 & 85 & 39.1 \\
\hline L7* & $\begin{array}{l}1.25 \% \text { Gel } \\
0.85 \% \text { GA }\end{array}$ & 0.5 & 2 & 125 & 85 & 61.1 \\
\hline L8 & \multirow{3}{*}{$3 \% \mathrm{EC}$} & 3 & 2.5 & 115 & 85 & 63.0 \\
\hline L9 & & 6 & 2.5 & 115 & 85 & 72.4 \\
\hline L10 & & 9 & 2.5 & 115 & 85 & 78.1 \\
\hline
\end{tabular}

The compressor and air circulation speed were operated at maximum. The experiments were carried out in a Lab Plant brand SD-Basic spray drying device with a main cabinet size of $380 \mathrm{~mm}$ x $110 \mathrm{~mm}$. The production yield of the lavender microcapsules was calculated according to the following equation:

$$
(\%) \text { Yield }=\frac{\text { Actual capsule amount }(g)}{\text { Theoritical capsule amount }(g)} \times 100
$$

Morphology of the microcapsules is a good indicator for ideal capsule formation. Therefore, scanning electron microscopy (SEM) micrographs were taken. The chemical properties of microcapsules were examined by Fourier transformed infrared (FT-IR) spectrometry. The thermal resistance of microcapsules and behaviour of the essential oil were investigated through thermogravimetric analysis and differential thermal analysis system (DT/TGA). The optimum microcapsule formulation was applied to the different knitted fabrics used in sports and leisure garments according to the exhaustion method. The fabrics were examined using SEM micrographs for the presence of capsules on the fabrics and the determination of the effect of domestic washing and rubbing. The effect of microcapsule finishing on colour was determined. The antibacterial effect of the microcapsule treated fabrics was studied according to AATCC 147 standard. Permeability properties were evaluated before and after microcapsule application regarding air permeability and water vapour permeability tests using ISO 9237 and BS 7209 standards respectively. 


\section{RESULTS AND DISCUSSIONS}

The composition of the lavender oil was revealed as $39.2 \%$ linalool and $34.7 \%$ linalyl acetate. The other active agents found in the essential oil were camphor, 1,8Cineole, $\beta$-ocimene, $\beta$-caryophyllene and borneol. Photomicrographss of gelatine, gelatine-gum arabic and ethyl cellulose micro particles formed using lavender oil are given in Figure 1. When the images of micro particles with 5\% gelatine concentration were examined (L1-L3), collapses were observed in the capsule structure. It was thought that this could be due to the relatively high temperature required to dry solutions with high polymer concentrations. The drying effect at lower temperature, provided by using a low polymer concentration, resulted in an improvement in the capsule morphology (L4-L6). A lower aggregation tendency was observed in L7 coded micro particles prepared using a combination of gelatine and gum arabic polymer. When the images of the L8, L9 and L10 samples, which were created using ethyl cellulose, were examined, it was determined that the micro particles obtained were small, spherical and had a smooth surface compared to other formulations. Microcapsules with ethyl cellulose walls were less likely to agglomerate, and the capsules were found to be more rounded. The production yield of the optimum formulation was calculated as $72.4 \%$, which has one of the highest yield.

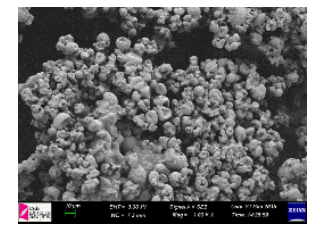

L1

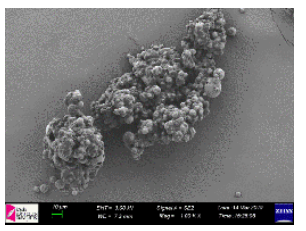

L6

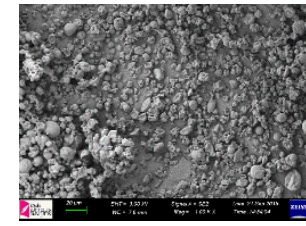

L2

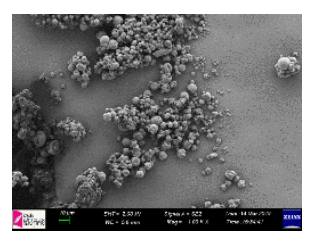

L7

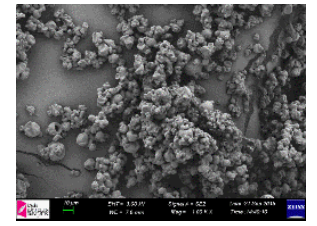

L3

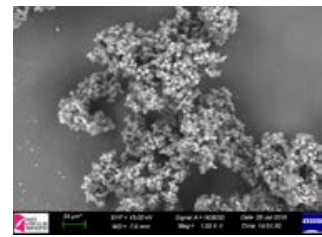

L8

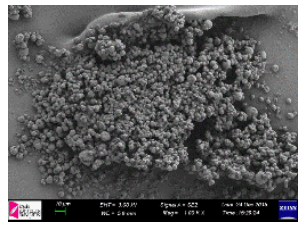

L4

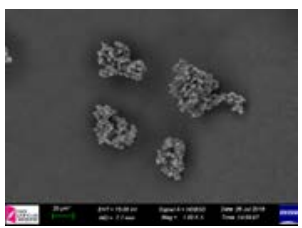

L9

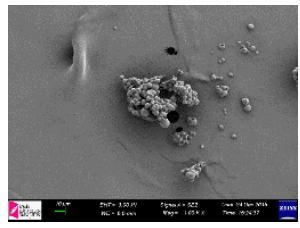

L5

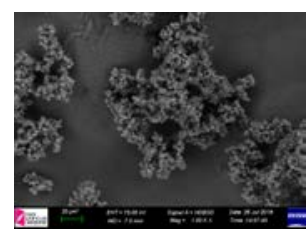

$\mathbf{L 1 0}$

Figure 1. SEM Micrograph of the optimum microcapsule formulation with lavender oil

When the spectrum of lavender oil was examined, the broad band of the $\mathrm{OH}$ groups was seen in the range of $3600-3200 \mathrm{~cm}^{-1}$, and the peak of the $\mathrm{CH}_{3}$ groups was around $2900 \mathrm{~cm}^{-1}$. The characteristic molecular groups of COOR and $\mathrm{C}=\mathrm{O}$ and the peak of $\mathrm{C}=\mathrm{O}$ stretching at $1735 \mathrm{~cm}^{-1}$ were determined. Both lavender and ethyl cellulose peaks were found in lavender microcapsules (figure 2). 


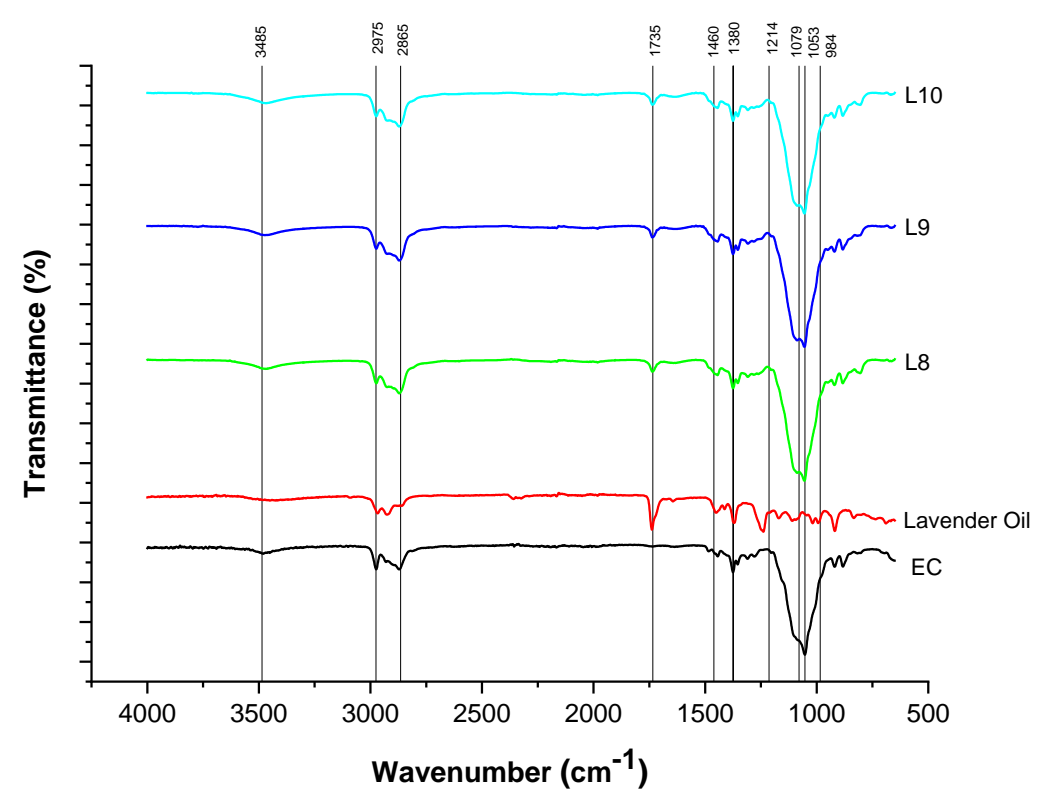

Figure 2. FT-IR Spectra of EC-Lavender capsules

TGA thermograms and DSC diagrams of ethyl cellulose, lavender oil and microcapsules formed with the oil are given in figure 3 .

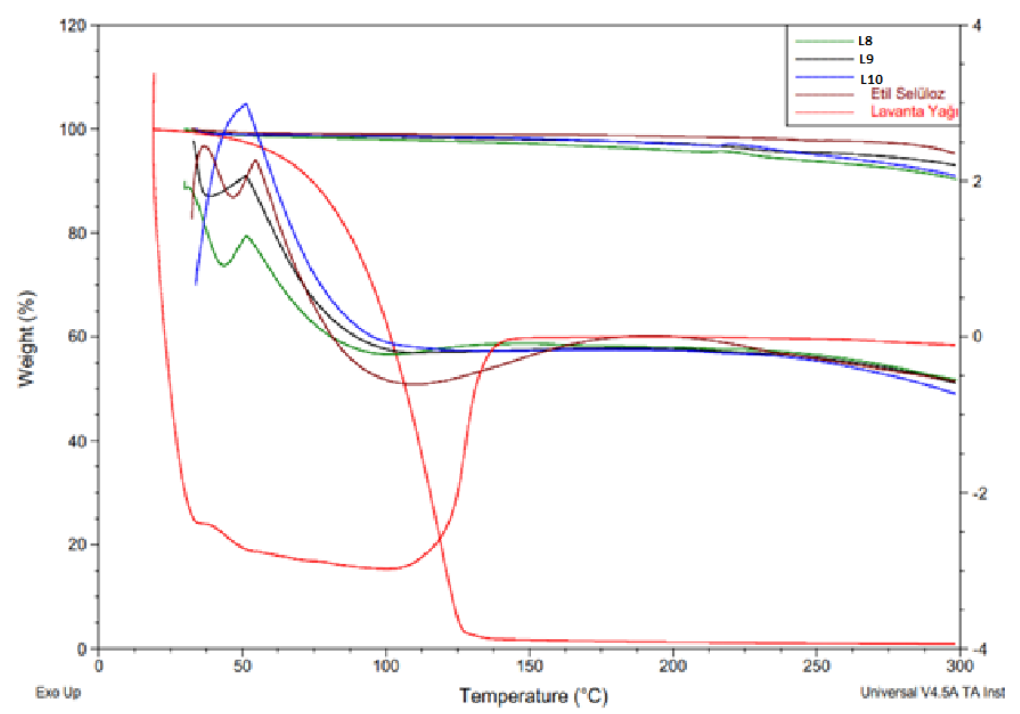

Figure 3. TGA thermograms and DSC diagrams of lavender oil and EC micro particles

When the TGA graph of ethyl cellulose is examined, a weight loss was observed at $100^{\circ} \mathrm{C}$ due to the moisture in the material. Pyrolysis starts around $225^{\circ} \mathrm{C}$ and accelerates at $300^{\circ} \mathrm{C}$. It is known that the degradation temperature of ethyl cellulose is around $440^{\circ} \mathrm{C}$ [4]. When the graphs of lavender oil are examined, it is seen that the weight loss starts around $35^{\circ} \mathrm{C}$ and degrades around $125^{\circ} \mathrm{C}$. A wide endothermic peak was observed in the range of $30-120^{\circ} \mathrm{C}$ in the DSC curve of lavender oil. TGA curves similar to ethyl cellulose were obtained when this oil, which evaporated at low temperatures, was confined to the ethyl cellulose shell. The mass loss at $150^{\circ} \mathrm{C}$, where lavender oil is completely decomposed, is around 5\% in L8, L9 and L10 formulations. 
SEM images of knitted fabrics with L9 formulation before washing, after 1 and 10 washings are shown in figure 4. It was determined that the micro particles were successfully transferred to all the fabrics. It has been observed that the micro particles on the fabric and in the fibre spaces are especially concentrated in the areas covered with binder. A low rate of removal of micro particles from the fabric surface after washing indicates that permanent bonding based on 10 washings is achieved.

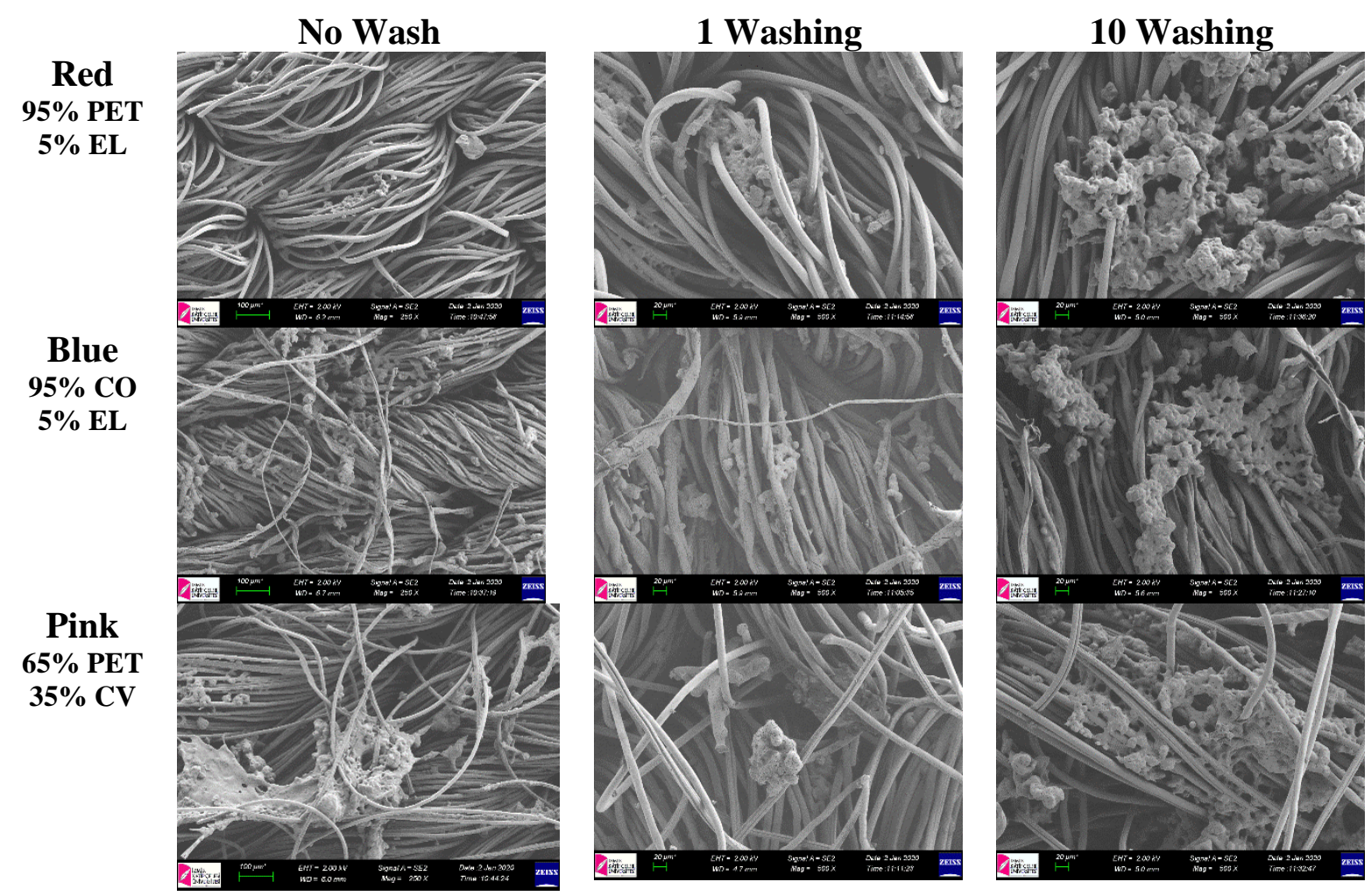

Figure 4. Washing resistance of fabrics containing lavender oil microcapsules

Another of the highest mechanical effects that leisure clothing faces is rubbing. It is important that the micro particles are permanently attached to the fabric exposed to friction. The images of the samples taken after the rub test from the lavender microcapsules applied fabrics are presented in figure 5. It was determined that the micro particles remained on the fabric after rubbing.

Antibacterial essay results on fabrics containing lavender oil capsules are given in table 2. Gram-negative and gram-positive bacterial types were heavily grown for the control samples. Zone of inhibition was not observed against both E. coli and S. aureus bacteria in lavender-containing fabrics and lower bacterial growth was observed on the contact surface.

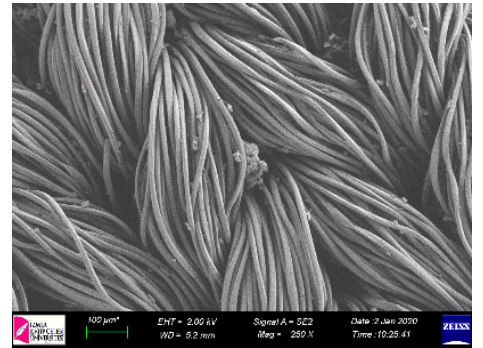

Red

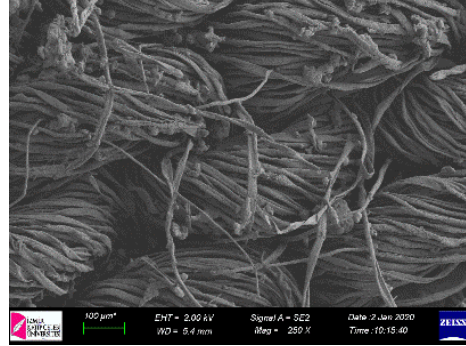

Blue

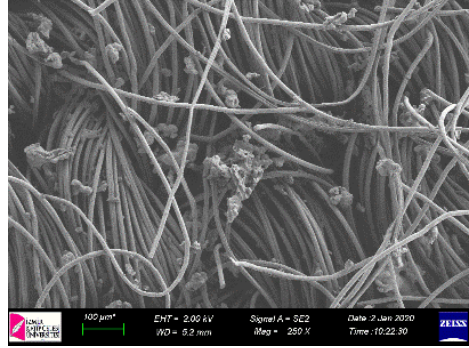

Pink

Figure 5. Rubbing resistance of fabrics containing lavender oil microcapsules 
Table 2. Antibacterial analysis results of fabrics containing lavender microcapsules

\begin{tabular}{|c|c|c|c|c|}
\hline \multirow{3}{*}{ Sample } & \multicolumn{2}{|c|}{ Gram Negative Bacteria } & \multicolumn{2}{|c|}{ Gram Pozitive Bacteria } \\
\hline & \multicolumn{2}{|r|}{ E.coli } & \multicolumn{2}{|c|}{ S.aureus } \\
\hline & $\begin{array}{l}\text { Inhibition } \\
\text { Zone }\end{array}$ & $\begin{array}{c}\text { Growth on the } \\
\text { Surface }\end{array}$ & $\begin{array}{c}\text { Inhibition } \\
\text { Zone }\end{array}$ & $\begin{array}{c}\text { Growth on the } \\
\text { Surface }\end{array}$ \\
\hline Control & Not observed & High bacterial growth & Not observed & High bacterial growth \\
\hline $\begin{array}{l}\text { Microcapsule Treated } \\
\text { Fabric }\end{array}$ & Not observed & $\begin{array}{l}\text { Medium bacterial } \\
\text { growth }\end{array}$ & Not observed & $\begin{array}{l}\text { Medium bacterial } \\
\text { growth }\end{array}$ \\
\hline
\end{tabular}

Permeability properties of the cotton fabrics were determined before and after microcapsule application. Accordingly, capsule application was decreased the permeability of the fabrics due to blocking the spaces. Theoretically, binder and microcapsule applications are expected to reduce the permeability of fabrics as they block the pores in the fabric. While pristine cotton fabrics have $298.3 \mathrm{~mm} / \mathrm{s}$ air permeability and $904.7 \mathrm{~g} / \mathrm{m}^{2} /$ day water vapour permeability, lavender capsule applied fabrics reveal 292.7 $\mathrm{mm} / \mathrm{s}$ and $813.5 \mathrm{~g} / \mathrm{m}^{2} /$ day, respectively. However, there was no statistically significant decrease in both air and water permeability results (figure 6).

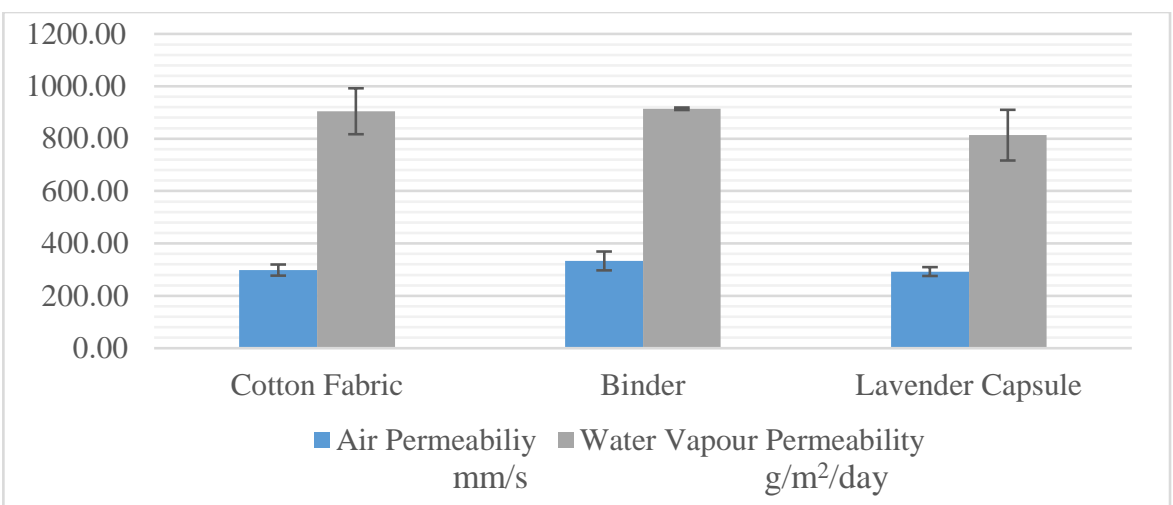

Figure 6. Permeability properties of fabrics containing lavender oil microcapsules

\section{CONCLUSION}

The aim of this study is to develop sports and leisure clothes containing nano and micro sized capsules with lavender oil. In the manufacture of the capsules, polymers that skin-safe are used as shell polymers. An industrially applicable method, the spray drying, was chosen as the capsule production technique. Lavender oil was selected to provide both aromatherapy effect and odour control that may occur during workout. The developed products have potential for commercialization and suitable for industrial production.

\section{ACKNOWLEDGMENT}

This work is produced by the project named "AromaTex" which is supported by MANUNET as international project collaboration between Romania and Republic of Turkey. It is funded by TUBITAK Scientific and Technological Research Council in the frame of the TEYDEB Project 917025 and by UEFISCDI as MNET17 / NMAT-1240. Also we acknowledge to Doğal Destek A.Ş. (Tabia). 


\section{REFERENCES}

[1] Ghosh, S.K., Functional coatings and microencapsulation: a general perspective, In: Ghosh S.K. (Ed.), Functional Coatings, WILEY-VCH Verlag GmbH \& Co. KGaA Weinheim, 2006, 1-28

[2] Salaün, F., Microencapsulation technology for smart textile coatings, In: Hu, J. (Ed), Active Coatings for Smart Textiles (Woodhead Publishing, 2016, 179-220

[3] Sienkiewicz, M., Lysakowska, M., Ciecwierz, J., et al., Antibacterial activity of thyme and lavender essential oils, In: Medicinal Chemistry, 2011, 7, 6, 674-689, https://doi.org/10.2174/157340611797928488

[4] Turkoğlu, G.C., Sarışık, A.M., Erkan, G., Kayalar, H., Kontart, O., Öztuna, S., Determination of antioxidant capacity of capsule loaded textiles, In: Indian Journal of Fibre \& Textile Research (IJFTR), 2017, 42, 2, 189-195 